\title{
Interactive comment on "At which time scale does the complementary principle perform best on evaporation estimation?" by Liming Wang et al.
}

\section{Anonymous Referee \#2}

Received and published: 25 August 2020

Ln 9. Suggest change "Energy correction methods" to "energy balance closure methods" Ln 154-157, does this mean that the two model parameters (i.e. $m$ and $n$ ) are determined from alpha and $b$ only? Ln171-177, What is the justification for the treatment of parameter alpha? Was the optimization done for each flux site at daily, weekly, monthly, and annul time scales respectively? Why was equation (5) was tested instead of (6)? Brutsaert (2015) suggested that "it is preferable to use equation (6) and the $c$ parameter should only be introduced to accommodate unusual situations." Ln220-227, The results shown in Figure 1 do not indicate the model performance at daily, weekly, monthly, and annual time scales. If the authors want to know how the model perform at these time scales, they need to show daily to annual results for each site and present a summary of the 88 flux sites. Ln 241 , Morton (1983) suggested that the complemen-

Printer-friendly version

Discussion paper 
tary relationship should be applied at longer time scales (e.g. monthly), but it does not explain why the weekly or monthly results are better than the daily results. Ln370, Figure 5 should be Figure 7. What is the significance of this relationship? Ln $409-436$, This section deals with the issue of the energy balance closure. To me, this is a separate question and I don't see the relevance to the performance of the complementary relationships.

Interactive comment on Hydrol. Earth Syst. Sci. Discuss., https://doi.org/10.5194/hess-2020379, 2020. 